\title{
IAA production and maize crop growth promoting potential of endophyte Aspergillus niger (AO11) under salt stress
}

\author{
Syed Muhammad Ziaullah*, Syed Asim, Aneesa Nayab, Asma Zahid
}

Department of Botany, Abdul Wali Khan University, Mardan, Khyber Pakhtunkhwa 23200, Pakistan

Received: August 07, 2019

Revised: July 29, 2020

Accepted: October 27, 2020

Published: November 11, 2020

*Corresponding Author:

Syed Muhammad Ziaullah

Email: syedziaullah420@gmail.

com

\begin{abstract}
Maize is cultivated under a broad range of soil conditions and environments. Maize is slightly vulnerable to salt stress and therefore it is seriously affected by soil salinity all over the world. Recognizing the responses of maize to salt stress and making a good strategy to overcome this problem could aid to develop solutions in saline areas to improve maize productivity. We investigated in this research the impacts, tolerance and salt stress management in corn. Many endophytic fungi can produce the Indole-3-acetic acid (IAA) is known for their role in plant growth and development both with and without salt stress conditions. The current study was focused on the production of IAA by endophytic fungi (Aspergillus niger) and maize seeds germination and promotion of seedling growth and vigor. In order to evaluate the defense response of maize plant, in relation to A. niger, an experiment was designed with three replications of treatments (control, salt stressed, salt stressed inoculated with A. niger, and only A. niger inoculated plants. It was determined that A. niger has the ability to produce the IAA in $\mathrm{NaCl}$ and $\mathrm{KCl}$ stress peaking $53 \mu \mathrm{g} / \mathrm{ml}$ and was not significantly by alternating the nitrogen and carbon sources in the nutrient broth but increasing the tryptophan concentration raised its production level. High concentration stress of sodium chloride and potassium chloride decrease maize plant seeds germination percentage, shoot and root length also affected the fresh and dry weight of maize. A. niger improves salt resistance in maize and also increased the germination percentage up to $30 \%$, also improved the chlorophyll level and it was proved an effective approach for improving maize germination and growth under salt stress.
\end{abstract}

KEYWORDS: Phytohormones, auxins, salt stress, symbiotic association, growth promotion

\section{INTRODUCTION}

Soils with dissolved residual salts are known as salt affected soils. Salt stress has now turn a severe danger to crops development in arid and semi-arid areas of the globe due to excess evaporation and poor-rainfall,combined with piteous land and water governance methods [1]. The generic view was that salinizations happen mostly in all areas of the world [2]. Internationally, more than 800 million hectares of soil are impacted by alkalinity (397 million hectares) or sodium toxicity (434 million hectares) [3]. Salt concentrations more than $0.25 \mathrm{M}$ affects corn crop and can inhibit development and trigger serious wilting [4]. Sodium was the primary hazardous ion which disrupts with potassium activity and therefore infuriates stomatal simulations exploit to severe evaporation and necrosis in maize [5]. Ultraosmotic stress as well as harmful impacts of sodium and chloride ions on seed germination in a salty area could prevent and limited germination [6] also the corn plants under saline stress noted with decrease chlorophyll a and $\mathrm{b}$ and carotenoids with a decrease in total photosynthetic activity [7]. Endophytes are described as microorganisms completely resident in cells of stem,roots or leafs of plants. Over one million fungal species are estimated to be found in distinct crops genera reflecting the hypervariety of endophytic fungi [8]. Endophytic fungi are one of the greatest suppliers of natural bioactive compounds that can be used in various fields, such as agriculture, healthcare and food technology $[9,10]$. A number of endophytes were investigated in order to develop growth-promoting metabolites comparable to those generated by their host crops, but in greater amounts [11]. Many fungal-endophytes are noted to enhance crop production in several ecosystems, [12]. Many endophytes were studied to ascertain their capacity for producing bioactive products comparable to those generated by their host crops [13] In several plants [14], symbiosotic endophytic pathogens have been observed to enhance plant growth. Auxins (IAA) and gibberellins (GA3, GA4 and GA7) were recorded to be produced

Copyright: $\odot$ The authors. This article is open access and licensed under the terms of the Creative Commons Attribution License (http:// creativecommons.org/licenses/by/4.0/) which permits unrestricted, use, distribution and reproduction in any medium, or format for any purpose, even commercially provided the work is properly cited. Attribution - You must give appropriate credit, provide a link to the license, and indicate if changes were made. 
by various types of endophytic fungi [15]. Plant species and microbes such as bacteria, algae and fungi can generate IAA which enhance plant growth [16]. The function of microbial IAA in relationship between plant and microbes has currently obtained greater focus [17]. Fungi-based IAA can lead to the formation and growth of root and root hairs leads to improved absorption of nutrients by the corresponding plants [18]. The role of fungal produced IAA in different plant-fungal interaction systems recommends that fungi can be associated to plant for pathogenesis or symbiotic approach using IAA and related compounds leading to plant growth promotion and changes in the basal defense mechanisms of the plant [19]. Endophytic fungi colonization and symbiosis improve salt resistance in maize due to better nutrient absorption, regulate potassium/ sodium ratios in plant tissues, better osmotic adjustments and also improved photosynthetic and water usage efficiencies under salt stress [20]. Production by microbes, plant hormones and biochemicals relies on factors such as $\mathrm{pH}$, temperature, incubation period, microbe types, development mechanisms and inner physiology [21]. Selection of optimal growth conditions is necessary to outline the strategies for production of GAs and other bioactive metabolites [22]. In current research IAA production of enophytic fungi (Aspergillus niger) under different salt stress conditions was determined and studied with combination of endophyte-maize plant growth promotion activities under salts stress conditions.

\section{METHODS AND MATERIALS}

Obtained from the Department of Botany, Abdul Wali Khan, University, Mardan, Pakistan, the endophyte Aspergillus niger strain (AOll) was cultured and purified on PDA media plates, containing (g L-1) potatoes, 200 gram; dextrose, $20 \mathrm{~g}$; agar $15.0 \mathrm{~g}$ per $1,000 \mathrm{~mL}$ of distilled water; $80 \mathrm{ppm}$ streptomycin; pH 5.6 0.2 [23]. Selected endophyte was grown with 100, 500 and $1000 \mu \mathrm{g}$ L-tryptophan in synthetic Czapek-Dox broth, incubated for 7 days at $30^{\circ} \mathrm{C}$ on rotary shaker (120 rpm) [23]. The IAA was measured by spectrophotometer (PerkinElmer Lambda 25) in the Aspergillus niger culture filtrate at $540 \mathrm{~nm}$ using Salkowski reagent $\left(150 \mathrm{~mL}\right.$ of concentrated $\mathrm{H}_{2} \mathrm{SO}_{4}, 250.50$ $\mathrm{mL}$ of distilled water, $\left.7.5 \mathrm{~mL} 0.5 \mathrm{M} \mathrm{FeCl}_{3} \cdot 6 \mathrm{H}_{2} \mathrm{O}\right)$ and quantified by IAA standard graph [24]. Aspergillus niger was cultured in czapek medium supplied with 100, 500 and $1000 \mathrm{mg} / \mathrm{L}$ of $\mathrm{NaCl}$ and $\mathrm{KCl}$ and effect of carbon sources (sugar and fructose) and nitrogen sources (beef and yeast extract) in czapek medium were also determined on its IAA production. The maize seeds (GAUHER) were received from the National Agriculture Research Center (NARC) Islamabad in order to determine the growth promoting ability of the selected fungal strain under influence of salt stress. The experiment was designed as Control (Ctrl), Aspergillus niger treated seeds (ANTS), $\mathrm{NaCl}$ 50,100 and $150 \mathrm{mM}$ stressed seeds (N50, N100 and N150), $\mathrm{NaCl} 50,100$ and $150 \mathrm{mM}$ stressed seeds in combination with Aspergillus niger (N50ANTS, N100ANTS and N150ANTS), $\mathrm{KCl} \mathrm{50,100} \mathrm{and} 150 \mathrm{mM}$ stressed seeds (K50, K100 and K150), $\mathrm{KCl} 50,100$ and $150 \mathrm{mM}$ stressed seeds in combination with Aspergillus niger (K50ANTS, K100ANTS and K150ANTS). Maize seeds (Zea maize L.) were surface disinfected for 5 min with $0.1 \% \mathrm{HgCl}_{2}$, depth in $70 \%$ ethyl alcohol for $2 \mathrm{~min}$ and washed five times with sterile distilled water. Surface disinfected maize seeds have been seeded at a distance of $5 \mathrm{~cm}$ in $500 \mathrm{~g}$ sterilized soil in plastic container supplied with $50 \mathrm{~g}$ of selected fungal biomass. Seedlings were watered frequently with distilled water and each container got the weekly nutrient of $300 \mathrm{ml}$ half strength sterile Hoagland solution [25]. The percentage of seed germination was calculated by GP $=\mathrm{Nf}$ * $100 / \mathrm{N}$. Where $\mathrm{N}$ is the total seeds count and $\mathrm{Nf}$ is the germinating seeds count [26]. According to Akhtar et al., (2015), chlorophyll content was calculated. Fresh $0.5 \mathrm{~g}$ leaves specimen from every treatment was crushed and dissolved in $80 \%$ acetone $(\mathrm{v} / \mathrm{v})$. The absorbance of chlorophyll a and b by the spectrometer was taken at 663 and $645 \mathrm{~nm}$ respectively [27], and calculated as:

Chl 'a' (mg/g fresh weight $)=[12.7($ O.D 663) $-2.69($ O.D 645) $\times \mathrm{V} / 1000 \times \mathrm{W}]$

Chl 'b’ (mg/g fresh weight $)=[22.9($ O.D 645) $-4.68($ O.D 663) $\times \mathrm{V} / 1000 \times \mathrm{W}]$

Where $\mathrm{V}$ is the volume of sample, $\mathrm{W}$ is weight of fresh tissue, O.D $480+0.114$ (O.D 663) - 0.638 (O.D 645). The Vigor Index of seeds $(\mathrm{SV})$ was determined with $\mathrm{VI}=\mathrm{SL} \times \mathrm{GP}$, where the germination percentage is (GP) and the length of the radicle plus plumule is (SL) [28]. After three weeks of growing seedlings, the radicle, plumule and complete seedling length were calculated using the measuring scale in centimeters

\section{RESULTS AND DISCUSSION}

The Apsrgillus niger was first grown on PDA plates where the colony of selected strain shown thousands of gray-green conidia along with the blue green mycelia (Figure 1). By colorimetric test using Salkowski reagent, the IAA was detected in the Aspergillus niger culture exrtacts. Many researchers revealed IAA production by many fungal-endophytes [29] the Aspergillus niger fungus gives IAA by $(85 \mu \mathrm{g} / \mathrm{mL})$ and T. Harzianum $(68 \mu \mathrm{g} / \mathrm{mL})$ as well as Penicillium citrinum produced $(52 \mu \mathrm{g} / \mathrm{mL})$ during incubation for three days of $30^{\circ} \mathrm{C}$. The very same investigation on the development of IAA by Aspergillus niger has been examined for 5-16 days with highest total increased production of 1.28 to $6.8 \mu \mathrm{g} / \mathrm{mL}$ was noted at 6 days of incubation in the CzapekDox broth with $0.1 \%$ tryptophan [30]. It was also reported that IAA production at $28^{\circ} \mathrm{C}$ was maximum $[31,32]$. IAA

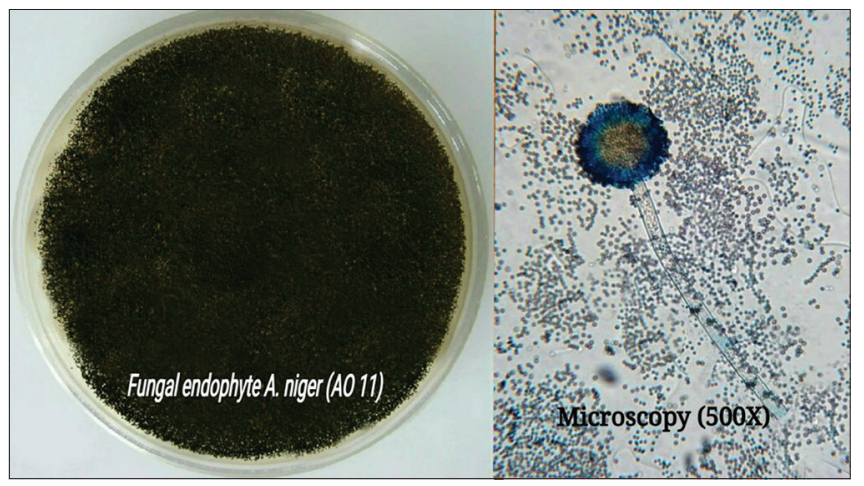

Figure 1: Aspergillus niger on PDA, and its microscopy at 500X showing spores and conidia along with mycelia 
production was not significantly influenced by replacing the carbon and nitrogen resources in broth, while enhancing the concentration of L-tryptophan from 500 to $1000 \mu \mathrm{g} / \mathrm{mL}$ considerably increased the quantity of IAA discharged. Assessed in nutrient broth under saline conditions the variability of IAA production with $\mathrm{NaCl}$ stress was shown by Aspergillus niger, with production threshold reaching $20 \mu \mathrm{g} / \mathrm{mL}$ at $150 \mathrm{mM} \mathrm{NaCl}$ and gave $23 \mu \mathrm{g} / \mathrm{mL}$ in $\mathrm{KCl} 150 \mathrm{mM}$ stress (Figure 2). In the existence of $200 \mu \mathrm{g}$ tryptophan, tryptamine and tryptophol (6.2, 9.8 and $38.55 \mu \mathrm{g} / \mathrm{mL}$ ) Trichoderma atroviride generates the larger quantity of IAA [33]. In sterile culture, majority of fungi can yield auxinic compounds [34]. Indole-3-acétic acid (IAA) is primarily manufactured with tryptophan by most of the species via the indole-3-Pyruvate and the tryptamines pathway, tryptophan often improved IAA biosynthesis by 2.7-folds, which depend on its accessibility [35]. The symbiotic association of Aspergillus niger with the maize crops under salinity was assessed in nursery studies due to the IAA production under different salt stress circumstances by this strain. When maize seeds were exposed to $150 \mathrm{mM} \mathrm{NaCl}$ stress, up to 50 percent less germination was recorded, but in the same case this was 30 percent in Aspergillus niger symbiotic association, raised germination percentage by 30\%. Our results are consistent with Minaxi et al., 2013, that also concluded that wheat inoculation with G. etunicatum enhanced its germination by $13.7 \%$ [36]. Compared with the control, all salt treatments have decreased the germination of maize seed, and the symbiotic association of the selected endophyte with maize in stress conditions remains significant, but in normal growth conditions this symbiotic association was highly significant (Figure 3). The concentration of chlorophyll in endophyte-free control plants was considerably greater, but it was more influential in the plants grown in normal growing conditions inoculated with Aspergillus niger. Our results are in compliance with the studies previously observed by Mathur and Vyas (2000) that show that AM root colonization has enhanced chlorophyll synthesis, with greater net $\mathrm{CO}_{2}$ absorption and plant growth [37]. Nursery treatments with A. niger isolates under $\mathrm{NaCl}$ improved $(P \leq 0.05)$ the leaf chlorophyll a and total chlorophyll of maize plants also same trend was noted for the $\mathrm{KCl}$ stress seedlings in symbiotic-association with this endophyte (Figure 4). Recent research shows that G. intraradices and T. intraradicesis being applied by Colla et al., (2015) considerably enhanced the quality of chlorophyll [38]. The present findings demonstrated a significant difference $(P<0.05)$ between treatments for shoot and root length. Endophyte-treated maize crops have greater shoot and root length compared to untreated stressed crops. The results of the inoculation of wheat with G. fasciculatum as well as G. etunicatum have been

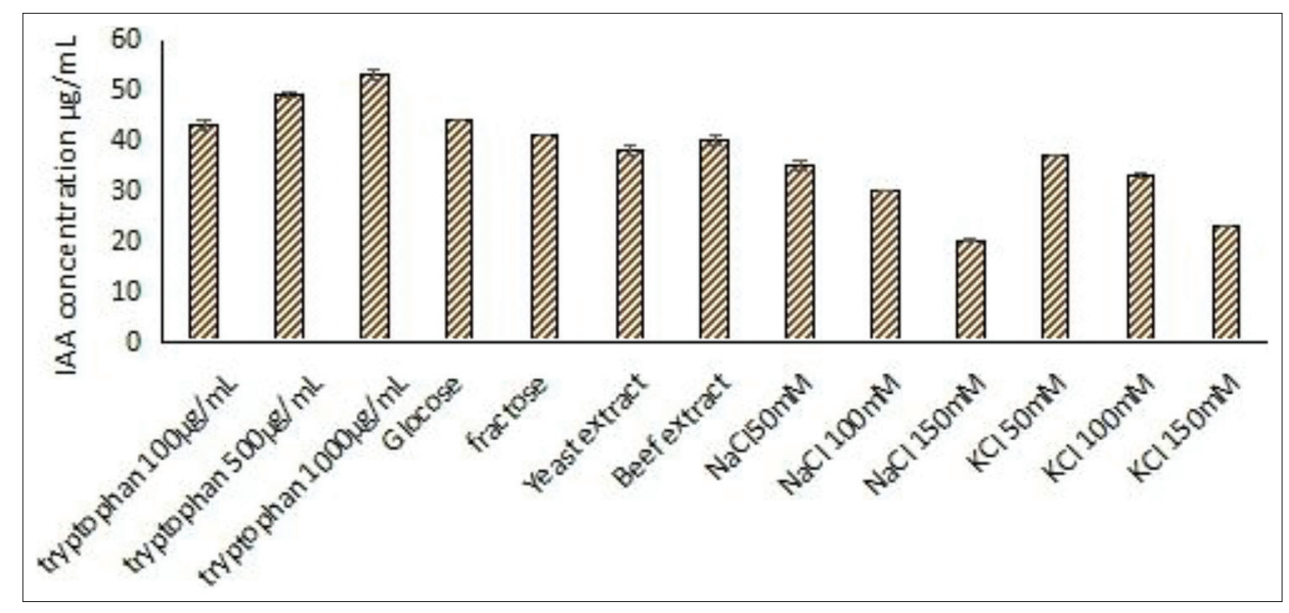

Figure 2: Effect of tryptophan, glucose, fructose, yeast extract, beef extract, $\mathrm{NaCl}$ and $\mathrm{KCl} 50,100$ and $150 \mathrm{mM}$ stress in nutrient broth on production of IAA by endophytic fungi Aspergillus niger

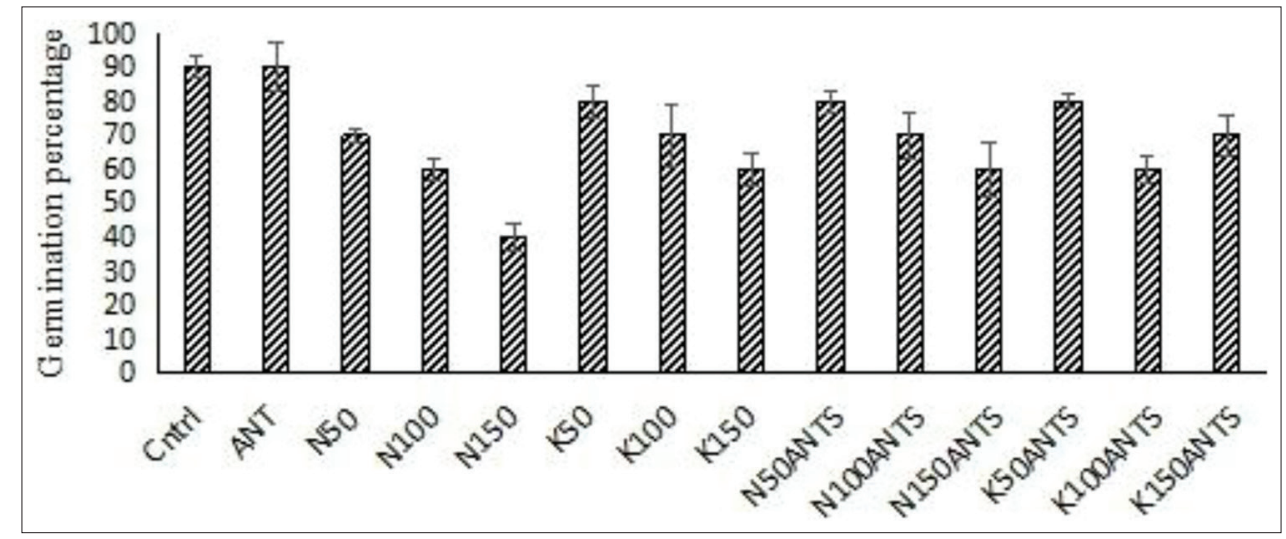

Figure 3: Germination percentage of maize seeds 


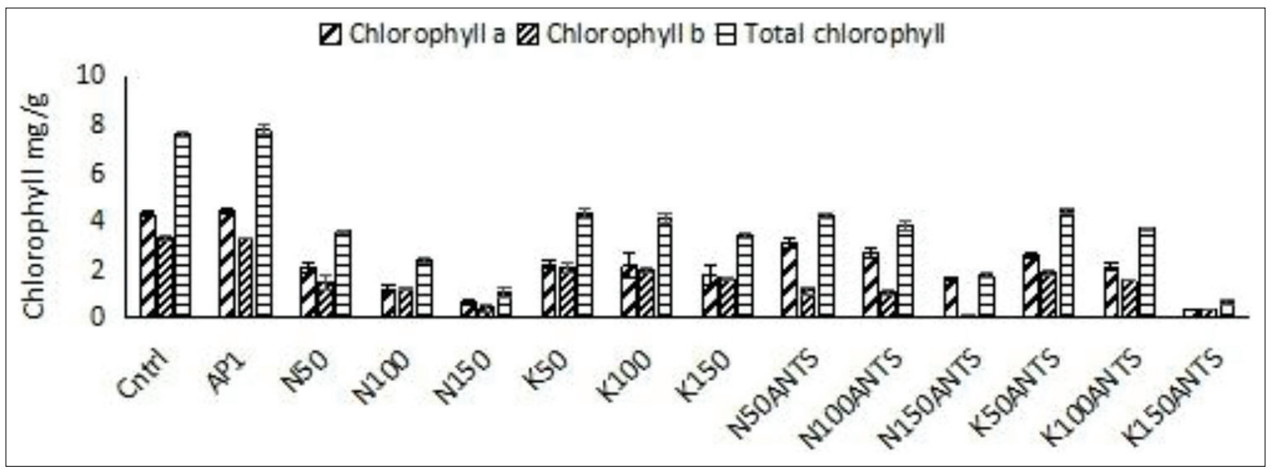

Figure 4: Chlorophyll content of maize seedlings

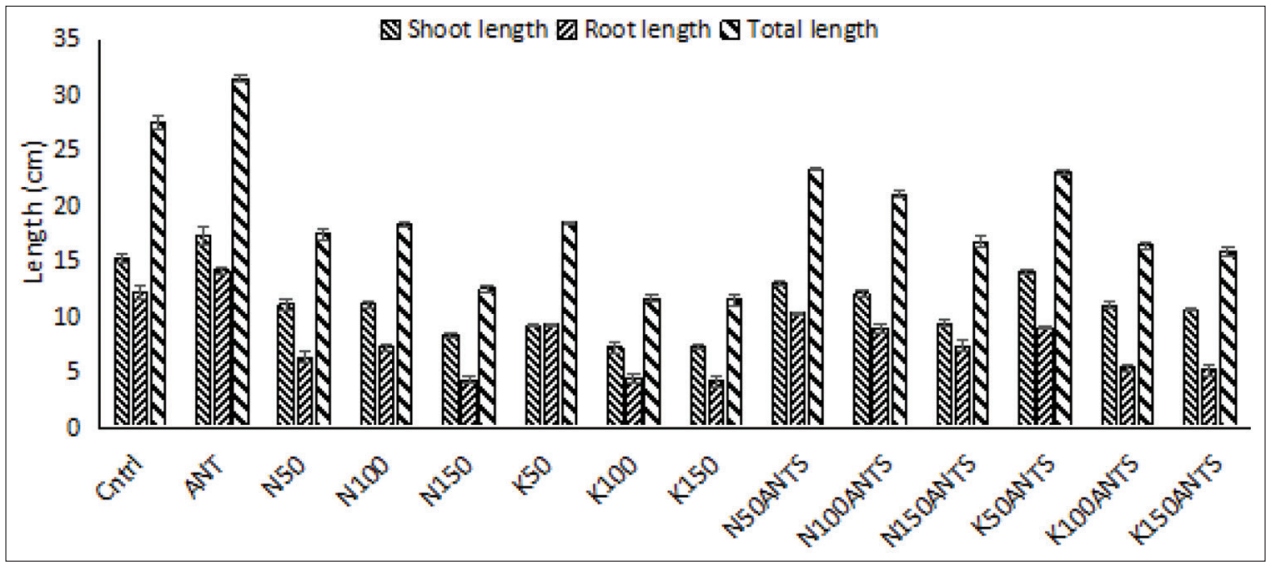

Figure 5: Root and shoot length of maize seedlings

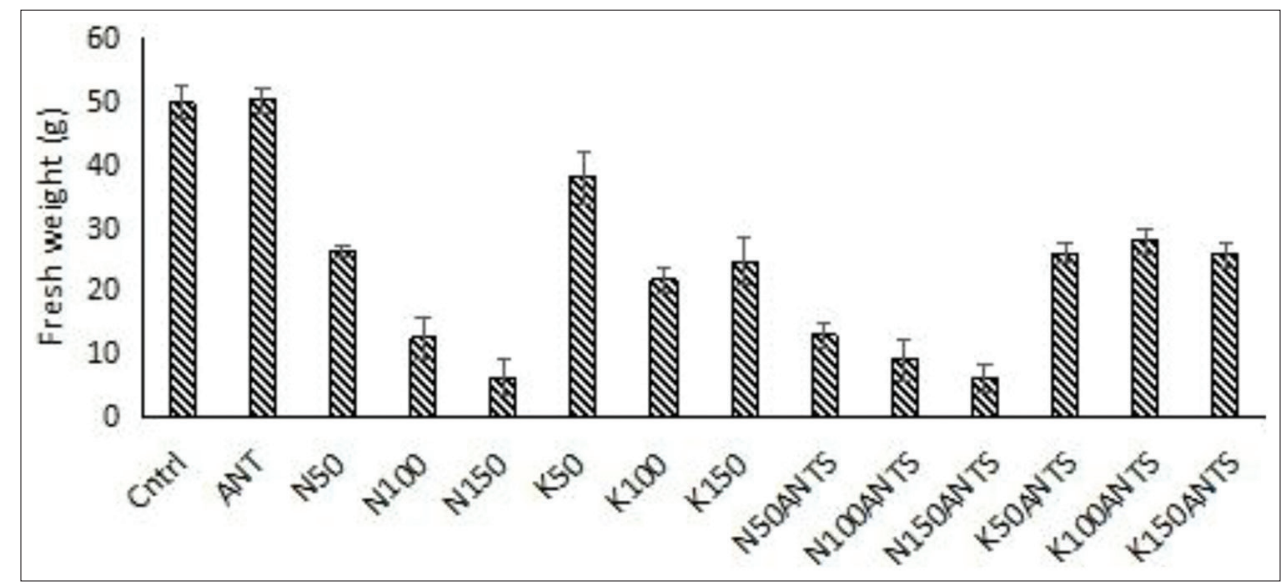

Figure 6: Fresh weight of maize plants

similarly observed for enhanced shoot and root dry weight, production of seeds and average height $[39,36]$. Endophyte considerably improves shoot length when contrasted to salinity stressed and the endophyte-free control treatments (Figure 5). All endophyte treatments have improved the fresh weight in both normal and salt stress conditions. Aspergillus niger's combination with maize has led to improved effects for fresh weight. There's always a mutualistic relationship in natural environments among crops and endophytic fungi [40]. Endophytic fungus manufactures some of the most important organic bioactive-compounds utilised in crops, healthcare as well as the food industry [41]. Endophytic fungi play an key part in crop defense and in developing crops perfect to tolerate biotic and abiotic stress, also help the crops in drought stress and increased biomass [42, 43]. Fresh weight values attained with endophyte cured crops significantly higher than those measured in salts stressed and control plants. The highest fresh weight was recorded from the ANT treatment, followed by control. Endophytic fungi could also improve crop growth, mainly because of development of endophyte-produced 


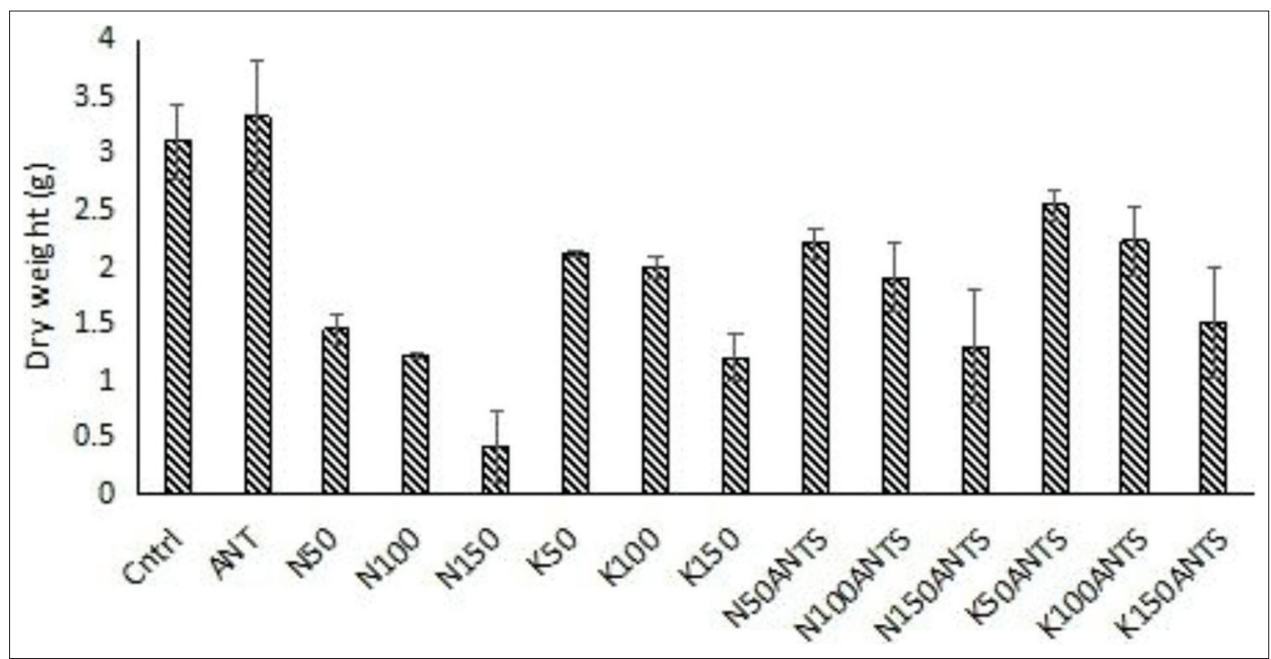

Figure 7: Dry weight of maize plants

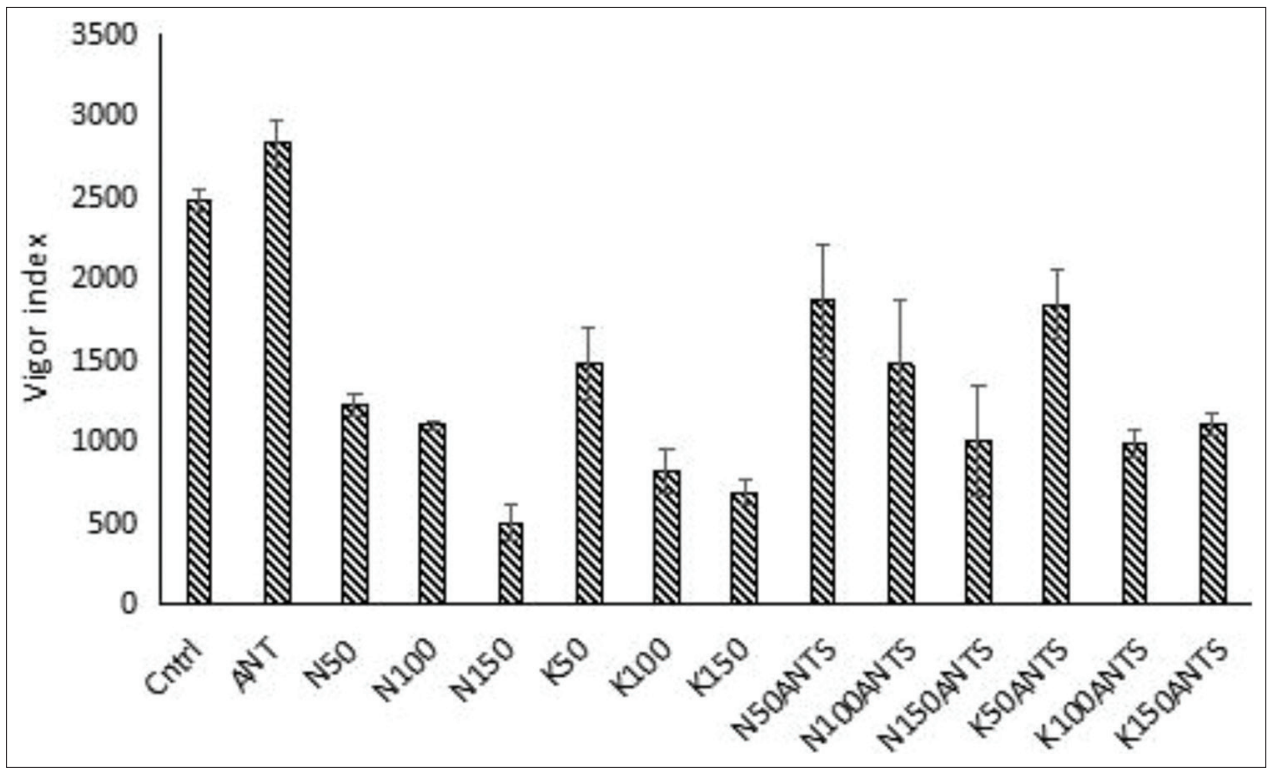

Figure 8: Vigor index of maize plants. Cntrl: control, ANT: Aspergillus niger treated plants N50, N100 and N150: NaCl 50,100 and 150 mM treated plants, K50, K100 and K150: KCl 50,100 and 150 mM treated plants, N50, N100ANTS, N150ANTS: Aspergillus niger with NaCl 50,100 and $150 \mathrm{mM}$ treated plants, K50, K100ANTS, K150ANTS: Aspergillus niger with KCl 50, 100 and $150 \mathrm{mM}$ treated plants. Data are mean of three replicates with standard error bars (Duncan test; $p<0.05$ )

phytohormones, such as IAA and GA, resulting to enhanced root development and enhanced nutritional uptake [44]. For plant dry biomass, the same phenomenon has been observed (Figures 6 and 7). Plants treated with A. Niger isolates had a significantly greater Vigor index value compared to stressed, control and endophyte treated plants in stress conditions. Treatment ANT indicated the high vigor index of maize plants with an increase of 12.37 times compared to control plants similarly the association of Aspergillus niger also improved the plant vigor index in salt stress compared to untreated stress plants (Figure 8). The endophyte has been used to secrete bioactive-compounds in its growing zone while the hormone shows significant impacts on plant growth both with and without stress circumstances [45]. A comparable behavior of an endophyte generating IAA was also determined, [46] where endophytic fungi manufacturing IAA increased the development of rice plants under the influence of salinity, cold and heat stress $[47,48]$. Hence our results are heavily supported by prior investigations.

\section{CONCLUSION}

In high salt stress circumstances Aspergillus niger was able to produce IAA in significant amount. Salt stress had a major impact on Maize crop. The germination of maize crop was drastically decreased by the $\mathrm{NaCl}$ and $\mathrm{KCl}$ stress as well as the development of its seedlings were noted reduced. The content of chlorophyll amount in the salt stress and without salt stress situations treated with Aspergillus niger was noted higher. However, it was greater in without salt stress treatments. Overall 
the Aspergillus niger has significantly improved the germination and growth of maize and helps to tolerate the severe salt stress conditions.

\section{REFRENCES}

1. Munns R. Comparative physiology of salt and water stress. Plant, Cell \& Environment. 2002; 2; 25 (2): 239-50.

2. Rengasamy P. World salinization with emphasis on Australia. Journal of Experimental Botany. 2006; 3; 1;57 (5):1017-23.

3. Munns R. Genes and salt tolerance: bringing them together. New Pytologist. 2005 9; 167(3): 645-63.

4. Menezes-Benavente L, Teixeira FK, Kamei CL, Margis-Pinheiro M. Salt stress induces altered expression of genes encoding antioxidant enzymes in seedlings of a Brazilian indica rice (Oryza sativa L.). Plant Science. 2004; 2; 166 (2) :323-31.

5. Sumer A. Evidence of sodium toxicity for the vegetative growth of maize during the first phase of salt stress. J. App. Bot.. 2004; 78: 135-9.

6. Farsiani A, Ghobadi ME. Effects of PEG and $\mathrm{NaCl}$ stress on two cultivars of corn (Zea mays L.) at germination and early seedling stages. World Acad. Sci. Eng. Tech. $2009 ; 9 ;$ 57: 382-5.

7. Qu C, Liu C, Gong X, Li C, Hong M, Wang L, Hong F. Impairment of maize seedling photosynthesis caused by a combination of potassium deficiency and salt stress. Environmental and Experimental Botany. $2012 ; 1 ; 75:$ 134-41.

8. Huang WY, Cai YZ, Xing J, Corke H, Sun M. A potential antioxidant resource: endophytic fungi from medicinal plants. Economic botany. $2007 ; 3 ; 61(1): 14$.

9. Strobel G, Daisy B, Castillo U, Harper J. Natural products from endophytic microorganisms. Journal of Natural products. $2004 ; 2$; 67(2): 257-68.

10. Verma VC, Kharwar RN, Strobel GA. Chemical and functional diversity of natural products from plant associated endophytic fungi. Natural product communications. 2009 ; 4 (11): 1934578X0900401114.

11. Zhao J, Zhou L, Wang J, Shan T, Zhong L, Liu X, Gao X. Endophytic fungi for producing bioactive compounds originally from their host plants. Current Research, Technology and Education Topics in Applied Microbiology and Microbial Biotechnology. 2010; 1: 567-76.

12. Angelard C, Colard A, Niculita-Hirzel H, Croll D, Sanders IR. Segregation in a mycorrhizal fungus alters rice growth and symbiosisspecific gene transcription. Current Biology. 2010; 7; 20 (13): 1216-21.

13. Zhao K, Penttinen P, Guan T, Xiao J, Chen Q, Xu J, Lindström K, Zhang L, Zhang X, Strobel GA. The diversity and anti-microbial activity of endophytic actinomycetes isolated from medicinal plants in Panxi plateau, China. Current microbiology. 2011 ; 1; 62 (1): 182-90.

14. Wijesooriya WA, Deshappriya N. An inoculum of endophytic fungi for improved growth of a traditional rice variety in Sri Lanka. Trop Plant Res. 2016; 3 (3): 470-80.

15. Khan AL, Hussain J, Al-Harrasi A, Al-Rawahi A, Lee IJ. Endophytic fungi: resource for gibberellins and crop abiotic stress resistance. Critical reviews in biotechnology. $2015 ; 1 ; 35(1)$ : 62-74.

16. Khan N, Bano A, Zandi P. Effects of exogenously applied plant growth regulators in combination with PGPR on the physiology and root growth of chickpea (Cicer arietinum) and their role in drought tolerance. Journal of plant interactions. $2018 ; 1 ; 13$ (1): 239-47.

17. Khan N, Bano A, Babar MA. The root growth of wheat plants, the water conservation and fertility status of sandy soils influenced by plant growth promoting rhizobacteria. Symbiosis. 2017; 6; 72 (3): 195-205

18. Contreras-Cornejo HA, Macías-Rodríguez L, Cortés-Penagos C, LópezBucio J. Trichoderma virens, a plant beneficial fungus, enhances biomass production and promotes lateral root growth through an auxin-dependent mechanism in Arabidopsis. Plant physiology. 2009 ; 3; 149 (3): 1579-92

19. Ludwig-Müller J. Plants and endophytes: equal partners in secondary metabolite production?. Biotechnology letters. 2015 ; $7 ; 37$ (7): 132534.

20. Farooq MS, Basra SM, Saleem BA, Nafees M, Chishti SA. Enhancement of tomato seed germination and seedling vigor by osmopriming. Pak. J. Agri. Sci. 2005; 42: 3-4.

21. Waqas M, Khan AL, Lee IJ. Bioactive chemical constituents produced by endophytes and effects on rice plant growth. Journal of plant interactions. 2014: 1: 9 (1): 478-87.

22 Albermann S, Elter T, Teubner A, Krischke W, Hirth T, Tudzynski B. Characterization of novel mutants with an altered gibberellin spectrum in comparison to different wild-type strains of Fusarium fujikuroi. Applied microbiology and biotechnology. 2013; 9; 97 (17): 7779-90.

23. Hamayun M, Khan SA, Khan AL, Shin JH, Ahmad B, Shin DH, Lee IJ. Exogenous gibberellic acid reprograms soybean to higher growth and salt stress tolerance. Journal of agricultural and food chemistry. 2010; 5; 58 (12): 7226-32.

24. Khan A, Hossain MT, Park HC, Yun DJ, Shim SH, Chung YR Development of root system architecture of Arabidopsis thaliana in response to colonization by Martelella endophytica YC6887 depends on auxin signaling. Plant and soil. 2016; 8; 405 (1-2): 81-96.

25. Zhou JY, Zhao XY, Dai CC. Antagonistic mechanisms of endophytic Pseudomonas fluorescens against A thelia rolfsii. Journal of Applied Microbiology. 2014; 10; 117 (4): 1144-58.

26. Gairola KC, Nautiyal AR, Dwivedi AK. Effect of temperatures and germination media on seed germination of Jatropha curcas Linn. Advances in bioresearch. 2011; 12; 2 (2): 66-71.

27. Akhtar SS, Andersen MN, Liu F. Residual effects of biochar on improving growth, physiology and yield of wheat under salt stress. Agricultural Water Management. 2015; 8; 158: 61-8.

28. Razmi Z, Hamidi R, Pirasteh-Anosheh H. Seed germination and seedling growth of three sorghum (Sorghum bicolor L.) genotypes as affected by low temperatures. International Journal of Farming and Allied Sciences. 2013; 2 (20): 851-6.

29. Yadav J, Verma JP, Tiwari KN. Plant growth promoting activities of fungi and their effect on chickpea plant growth. Asian J Biol Sci. 2011; 4 (3): 291-9.

30. Bilkay IS, Karakoc Ş, Aksoz N. Indole-3-acetic acid and gibberellic acid production in Aspergillus niger. Turkish Journal of Biology. 2010; 12; 34 (3): 313-8

31. Gunasekaran M. Physiological studies on Phymatotrichum omnivorum. Synthesis of indole acetic acid in vitro. Microbios. 1978; 22 (88): 85-91.

32. Hasan HA. Gibberellin and auxin-indole production by plant rootfungi and their biosynthesis under salinity-calcium interaction. Acta microbiologica et immunologica Hungarica. 2002; 3; 49 (1): 105-18.

33. Buckley NG, Pugh GJ. Auxin production by phylloplane fungi. Nature. 1971; 6; 231 (5301): 332

34. Gravel V, Antoun H, Tweddell RJ. Growth stimulation and fruit yield improvement of greenhouse tomato plants by inoculation with Pseudomonas putida or Trichoderma atroviride: possible role of indole acetic acid (IAA). Soil Biology and Biochemistry. 2007; 8; 39 (8): 1968-77.

35. Tudzynski B, Sharon A. Biosynthesis, biological role and application of fungal phytohormones. InIndustrial Applications 2002; 183-211.

36. Minaxi J, Chandra S, Nain L. Synergistic effect of phosphate solubilizing rhizobacteria and arbuscular mycorrhiza on growth and yield of wheat plants. Journal of Soil Science and Plant Nutrition. 2013; 13 (2): 511-25.

37. Mathur N, Vyas A. Influence of arbuscular mycorrhizae on biomass production, nutrient uptake and physiological changes in Ziziphus mauritiana Lam. under water stress. Journal of Arid Environments. 2000; 8; 45 (3): 191-5

38. Colla G, Rouphael Y, Di Mattia E, El-Nakhel C, Cardarelli M. Co-inoculation of Glomus intraradices and Trichoderma atroviride acts as a biostimulant to promote growth, yield and nutrient uptake of vegetable crops. Journal of the Science of Food and Agriculture. 2015; 6; 95 (8): 1706-15.

39. Bahrani A, Pourreza J, Joo MH. Response of winter wheat to coinoculation with Azotobacter and arbuscular mycorrhizal fungi (AMF) under different sources of nitrogen fertilizer. American-Eurasian Journal of Agricultural and Environmental Science. 2010; 8 (1): 95103.

40. Zhao J, Zhou L, Wang J, Shan T, Zhong L, Liu X, Gao X. Endophytic fungi for producing bioactive compounds originally from their host plants. Current Research, Technology and Education Topics in Applied Microbiology and Microbial Biotechnology. 2010; 1: 567-76.

41. Rodriguez RJ, White Jr JF, Arnold AE, Redman AR. Fungal endophytes: diversity and functional roles. New Phytologist. 2009; 4; 182 (2): 314-30

42. Liu C, Liu T, Yuan F, Gu Y. Isolating endophytic fungi from evergreen 
plants and determining their antifungal activities. African Journal of Microbiology Research. 2010; 11; 4 (21): 2243-8.

43. Rim SO, Lee JH, Khan SA, Lee IJ, Rhee IK, Lee KS, Kim JG. Isolation and identification of fungal strains producing gibberellins from the root of plants. Microbiology and Biotechnology Letters. 2007;35(4):357-63.

44. Egamberdieva D, Kucharova Z. Selection for root colonising bacteria stimulating wheat growth in saline soils. Biology and Fertility of Soils. 2009; 71; 45 (6): 563-71.

45. Dai CC, Yu BY, Li X. Screening of endophytic fungi that promote the growth of Euphorbia pekinensis. African Journal of Biotechnology.
2008; 7 (19).

46. Mei C, Flinn BS. The use of beneficial microbial endophytes for plant biomass and stress tolerance improvement. Recent Patents on Biotechnology. 2010; 1; 4 (1): 81-95.

47. Zandavalli RB, Dillenburg LR, de Souza PV. Growth responses of Araucaria angustifolia (Araucariaceae) to inoculation with the mycorrhizal fungus Glomus clarum. Applied Soil Ecology. 2004; 3; 25 (3): 245-55.

48. Al-Karaki GN, Hammad R, Rusan M. Response of two tomato cultivars differing in salt tolerance to inoculation with mycorrhizal fungi under salt stress. Mycorrhiza. 2001; 5;11 (1): 43-7. 